\title{
Presence/Absence of Two Types of Z-DNA Binding Domains in the Genomes of Organisms from Archaea, Bacteria, and Eukaryotes and Its Implications
}

\section{Hiroshi Nakashima}

Department of Clinical Laboratory Science, Graduate Course of Medical Science and Technology, School of Health Sciences, Kanazawa University, Kanazawa, Japan

Correspondence to: Hiroshi Nakashima, hinaka@staff.kanazawa-u.ac.jp

Keywords: Z-DNA Binding Domain, recA Protein, Adenosine Deaminase Acting on RNA, Genome Sequence Analysis

Received: December 5, 2018 Accepted: January 21, 2019 Published: January 24, 2019

Copyright $\odot 2019$ by authors and Scientific Research Publishing Inc.

This work is licensed under the Creative Commons Attribution International License (CC BY 4.0).

http://creativecommons.org/licenses/by/4.0/

\section{(c) (1) Open Access}

\section{ABSTRACT}

We conducted genome sequence analysis to examine the presence/absence of two types of Z-DNA binding domains in various organisms. We examined 68 organisms from archaea, 914 organisms from bacteria, and 199 organisms from eukaryotes. RecA protein from Escherichia coli has a Z-DNA binding domain and this protein promotes homologous recombination. All the organisms examined had this domain. This result indicated that this domain is essential for all the organisms. RNA editing enzyme, adenosine deaminase from human has another type of Z-DNA binding domain. This domain was observed in some organisms of archaea, bacteria, and eukaryotes. The presence/absence of Z-DNA binding domain in adenosine deaminase indicated that gain and loss of this domain had occurred in the process of evolution. The implication of presence and absence of this domain is discussed in this study.

\section{INTRODUCTION}

Double-stranded DNA is in equilibrium between right-handed B-DNA and left-handed Z-DNA. The B-DNA form is dominant and Z-DNA form makes only a small contribution to the equilibrium. It is reported that Z-DNA can be stabilized by cations and anions, dehydrating solvents, numerous covalent modifications of DNA, negative supercoiling, and Z-DNA binding proteins [1]. Segments of DNA with alternating $d(C G)$ sequences are the most favored for forming Z-DNA. Z-DNA binding proteins have been identified on the basis of their preferential binding to segments of Z-DNA, and they have been isolated from Drosophila melanogaster [2], rat brain neurons [3], wheat germ [4], bull testis [5], Escherichia 
coli [6, 7], Deinococcus radiodurans [8], chicken [9], and human [10]. The three-dimensional (3D) structures of Z-DNA binding domain from human [11-14] revealed that it differs from that of E. coli [15]. This result indicated that there are at least two types of Z-DNA binding domains. The recA protein from $E$. coli has Z-DNA binding domain, this protein promotes homologous recombination and it has Z-DNA stimulated ATPase activity [6]. RecA has multiple activities, all related to DNA repair. The RNA editing enzyme, adenosine deaminase acting on RNA (ADAR) from human includes Z-DNA binding domain [10] and this domain acts as an effector of gene expression [16].

We assumed that the presence/absence of Z-DNA binding domain would give the clues to the function and evolution of Z-DNA binding proteins. We expected the survey of genome sequences would reveal the presence/absence of Z-DNA binding domain, as genome sequence has all protein information the organism has. We conducted genome sequence analysis to examine the presence/absence of two types of Z-DNA binding domains in various organisms from archaea, bacteria, and eukaryotes using the database of genomes to protein structures and functions (GTOP) [17, 18]. GTOP provides protein annotation of 3D structures and functions based on homology search against Protein Data Bank [19, 20] and Structural Classification of Proteins (SCOP) [21] database protein sequences of known structure. We used GTOP because it has a powerful search aid by keyword to survey the query protein fold prediction in genome sequences.

\section{MATERIALS AND METHODS}

\subsection{Estimation of Presence/Absence of Z-DNA Binding Domain}

The determination of presence/absence of Z-DNA binding domain in organisms was simply done by using GTOP database. GTOP is containing protein fold predictions based on homology search against protein sequences of known structure. If there was a homologous hit for the Z-DNA binding domain with an e-value less than $10^{-10}$, it is estimated that the organism has the Z-DNA binding domain. If there was no hit, it is considered that the Z-DNA binding domain is absent in the organism.

\subsection{Protein Domain Structure}

The amino acid sequences of Z-DNA binding domain of $E$. coli recA protein and that of human ADAR protein from GTOP are shown in Figure 1(a) and Figure 1(b), respectively. GTOP uses Swiss-Prot protein sequence database [22], so the Swiss-Prot codes are given for the sequences.

GTOP adopted SCOP classification of protein structures, the unit of classification is usually the protein domain. SCOP organizes protein structures according to evolutionary origin and structure similarity. Actually, protein domains are classified on hierarchical levels into four categories: class, fold, superfamily, and family. The 3D structure of recA protein from E. coli has a domain described as class: alpha and beta

DENKQKALAAALGQIEKQFGKGSIMRLGEDRSMDVETISTGSLSLDIALG
AGGLPMGRIVEIYGPESSGKTTLTLQVIAAAQREGKTCAFIDAEHALDPI
YARKLGVDIDNLLCSQPDTGEQALICDALARSGAVDVIVVDSVAALTPK
AEIEGEIGDSHMGLAARMMSQAMRKLAGNLKQSNTLLIFINQIRMKIGVM
FGNPETTTGGNALKFYASVRLDIRRIGAVKEGENVVGSETRVKVVKNKIA
APFKQAEFQILYGEGI

(a)

SIYQDQEQRILKFLEELGEGKATTAHDLSGKLGTPKKEINRVLYSLAKKG KLQKEAGTPPLWKIA

(b)

Figure 1. (a) Amino acid sequence of E. coli recA protein Z-DNA binding domain. Swiss Prot: RECA_ECOLI [residues 4 to 269]; (b) Amino acid sequence of human adenosine deaminase acting on RNA Z-DNA binding domain. Swiss Prot: DSRAD_HUMAN [residues 134 to 198]. 
protein, fold: $\mathrm{p}$-loop containing nucleotide triphosphate hydrolases, superfamily: $\mathrm{p}$-loop containing nucleotide triphosphate hydrolases, family: recA protein-like (ATPase-domain). This domain is described as c.37.1.11 in SCOP code, and this is used as a keyword in GTOP search. Another Z-DNA binding domain in ADAR from human is described as class: all alpha protein, fold: DNA/RNA-binding 3-helical bundle, superfamily: winged helix DNA-binding protein, and family: Z-DNA binding domain. This domain is expressed as a.4.5.19 in SCOP code and used as a keyword in GTOP search. As more genomic sequences become available, the survey of proteins becomes difficult without useful tools. GTOP has a tool of keyword search on the web. For example, we searched the Z-DNA binding domain in GTOP using c.37.1.11 as keyword, then the homologous proteins in an organism were displayed with e-values. Therefore, we can simply estimate the presence or absence of the Z-DNA binding domain.

\section{RESULTS}

\subsection{Classification of Organisms}

We employed GTOP for the search of two types of Z-DNA binding domains. In GTOP, organisms are classified based on the annotation in the genome sequence according to hierarchy: three kingdoms (archaea, bacteria, and eukaryotes), phylum, and section. In GTOP, 68 organisms in archaea were divided into 5 phyla and 13 sections (Table 1(a)), 914 organisms in bacteria were divided into 21 phyla and 45 sections (Table 1(b)), and 199 organisms in eukaryotes were divided into 13 phyla and 21 sections (Table $1(c))$.

\subsection{Two Types of Z-DNA Binding Domains}

The Z-DNA binding domain in recA protein from E. coli was observed in all the sections of archaea, bacteria, and eukaryotes in GTOP. Therefore, there is no need to distinguish the presence/absence of the $\mathrm{Z}$-DNA binding domain in recA protein. This result indicated that this domain is essential for all the organisms.

Table 1. (a) Organisms that have Z-DNA binding domain in archaea; (b) Organisms that have Z-DNA binding domain in bacteria; (c) Organisms that have Z-DNA binding domain in eukaryotes.

(a) Archaea

\begin{tabular}{ccc}
\hline Phylum & Section & Organism \\
\hline Crenarchaeota & Thermoprotei & Hyperthermus butylicus \\
Euryarchaeota & Archaeoglobi & Archaeoglobus fulgidus \\
Halobacteria & Methanobacteria & \\
Methanococci & Methanomicrobia \\
Methanopyri & Methanococcoides burtonii \\
Thermococci & Thermococcus onnurineus \\
Thorarchaeota & Candidatus Korarchaeum & \\
Nanoarchaeota & Nanoarchaeum & Candidatus Korarchaeum cryptofilum \\
Thaumarchaeota & Cenarchaeales & \\
& marine archaeal & Nitrosopumilus maritimus \\
\hline
\end{tabular}


(b) Bacteria

\begin{tabular}{|c|c|c|}
\hline Phylum & Section & Organism \\
\hline \multirow[t]{3}{*}{ Acidobacteria } & Acidobacteriales & \\
\hline & Candidatus Koribacter. & \\
\hline & Solibacteres & \\
\hline \multirow[t]{4}{*}{ Actinobacteria } & Acidimicrobidae & \\
\hline & Actinobacteridae & \\
\hline & Coriobacteridae & \\
\hline & Rubrobacteridae & \\
\hline Aquificae & Aquificales & Persephonella marina \\
\hline \multirow[t]{4}{*}{ Bacteroidetes } & Bacteroidia & \\
\hline & Candidatus Amoebophilus & \\
\hline & Flavobacteria & \\
\hline & Sphingobacteria & \\
\hline Chlamydiae & Chlamydiales & \\
\hline Chlorobi & Chlorobia & Chlorobaculum parvum \\
\hline \multirow[t]{4}{*}{ Chloroflexi } & Chloroflexales & \\
\hline & Dehalococcoidetes & \\
\hline & Herpetosiphonales & \\
\hline & Thermomicrobiales & \\
\hline \multirow[t]{6}{*}{ Cyanobacteria } & Acaryochloris. & \\
\hline & Chroococcales & \\
\hline & Gloeobacteria & \\
\hline & Nostocales & \\
\hline & Oscillatoriales & \\
\hline & Prochlorales & \\
\hline Deinococcus-Thermus & Deinococci & \\
\hline Dictyoglomi & Dictyoglomia & \\
\hline Elusimicrobia & Elusimicrobiales & \\
\hline \multirow[t]{2}{*}{ Firmicutes } & Bacilli & Enterococcus faecalis \\
\hline & Clostridia & Thermoanaerobacter tengcongensis \\
\hline Fusobacteria & Fusobacteriales & \\
\hline Gemmatimonadetes & Gemmatimonadales & \\
\hline Nitrospirae & Nitrospirales & \\
\hline Planctomycetes & Planctomycetacia & \\
\hline \multirow[t]{2}{*}{ Proteobacteria } & Alphaproteobacteria & \\
\hline & Betaproteobacteria & Burkholderia xenovorans \\
\hline
\end{tabular}




\section{Continued}

\begin{tabular}{|c|c|c|}
\hline & Deltaproteobacteria & Desulfovibrio vulgaris \\
\hline & Epsilonproteobacteria & Nitratiruptor sp. SB155-2 \\
\hline & Gammaproteobacteria & \\
\hline & Magnetococcus & \\
\hline Spirochaetes & Spirochaetales & \\
\hline Tenericutes & Mollicutes & \\
\hline Thermotogae & Thermotogales & Fervidobacterium nodosum \\
\hline \multirow[t]{3}{*}{ Verrucomicrobia } & Methylacidiphilales & \\
\hline & Opitutae & \\
\hline & Verrucomicrobiae & \\
\hline \multicolumn{3}{|c|}{ (c) Eukaryotes } \\
\hline Phylum & Section & Organism \\
\hline Alveolata & Apicomplexa & \\
\hline Amoebozoa & Mycetozoa & \\
\hline Choanoflagellida & Codonosigidae & \\
\hline Cryptophyta & Pyrenomonadales & \\
\hline Euglenozoa & Kinetoplastida & \\
\hline Fornicata & Diplomonadida & \\
\hline \multirow[t]{5}{*}{ Fungi } & Chytridiomycota & \\
\hline & Dikarya & \\
\hline & Fungi incertae sedis & \\
\hline & Microsporidia & \\
\hline & Ichthyosporea & \\
\hline Haptophyceae & Isochrysidales & \\
\hline Heterolobosea & Schizopyrenida & \\
\hline Metazoa & Eumetazoa & Homo sapiens (human) \\
\hline & Placozoa & \\
\hline Rhodophyta & Bangiophyceae & \\
\hline \multirow[t]{2}{*}{ Viridiplantae } & Chlorophyta & \\
\hline & Streptophyta & \\
\hline \multirow[t]{3}{*}{ Stramenopiles } & Bacillariophyta & \\
\hline & Oomycetes & \\
\hline & Pelagophyceae & \\
\hline
\end{tabular}


Another Z-DNA binding domain in ADAR from human was observed in some organisms of archaea, bacteria, and eukaryotes, respectively. The representative organism in the column of organism in Tables 1(a)-(c) indicates the presence of Z-DNA binding domain in ADAR from human. The white space in the column of organism means the absence of this domain.

\subsection{Z-DNA Binding Domain from Archaea, Bacteria, and Eukaryotes}

Comparisons of the ribosomal RNA sequences from various organisms are commonly used to deduce the phylogenetic trees [23]. The trees indicate clustered classification into three kingdoms, archaea, bacteria, and eukaryotes, and sub-clustered groups into phyla and sections according to their sequence similarities. The phylogenetic tree based on archaeal $16 \mathrm{~S}$ small subunit ribosomal RNA sequences revealed that phylum Thaumachaeota may emerge before the divergence between Crenarchaeota and Euryarchaeota [24]. The presence of Z-DNA binding domain in the organisms belongs to the phyla Thaumachaeota, Crenarchaeota and Euryarchaeota suggested that the emergence of the Z-DNA binding domain was preceding to the branch between Crenarchaeota and Euryarchaeota (Table 1(a)). Four organisms, H. butylicus, A. fulgidus, T. onnurineus, and Candidatus $K$. cryptofilum are thermophiles, and M. burtonii and $N$. maritimus are mesophililes (Table 1(a)). This result suggested that the Z-DNA binding domain is favorable in thermophiles.

The evolutionary history of organisms of bacteria can be obtained by a comparison of conserved protein sequences of elongation factor- 1 alpha/Tu or $70-\mathrm{kDa}$ heat shock protein [25]. A clear separation of the Gram-positive and Gram-negative bacteria can be obtained. The phylum firmicutes only indicated the presence of Z-DNA binding domain in the Gram-positive bacteria (Table 1(b)), and the organisms have low $\mathrm{G}+\mathrm{C}$ content. In Gram-negative bacteria, the phyla of aquificae, chlorobi, proteobacteria and thermotogae showed the presence of Z-DNA binding domain (Table 1(b)), and their G + C content ranged from $35 \%$ to $67 \%$ among the organisms. The organisms of $P$. marina, T. tengcongensis, Nitratiruptor sp., and $F$. nodosum are thermophiles.

The Z-DNA binding domain was observed only in the organisms belong to phylum metazoan, section eumetazoa in eukaryotes (Table $1(\mathrm{c})$ ). It was interesting that only vertebrates indicated the presence of this domain and invertebrates indicated the absence of this domain. Mammalian genomes encode three ADAR genes, ADAR1, ADAR2 and ADAR3 [26, 27]. ADAR1 contains two Z-DNA binding domains, but not ADAR2 nor ADAR3. The ADAR genes are present in Caenorhabditis elegans genome [28], Drosophila genome [29], squid nervous system [30], and their ADAR gene products have no Z-DNA binding domain [31]. The ADAR family catalyzes the conversion of adenosine to inosine in pre-mRNA, and the substrates require duplex RNA secondary structure. Adenosine to inosine editing modulates the calcium permeability of neural glutamate receptors [32] and reduces the G-protein coupling efficiency of serotonin 2C receptors [33].

\section{DISCUSSION}

As mentioned above, the Z-DNA binding proteins have been isolated from various organisms based on the measurements of the interactions between Z-DNA and its binding proteins. The presence of the Z-DNA binding domain in various organisms is consistent with the result that the Z-DNA binding domain in recA protein was observed in all the organisms examined. It is reported that the experiments of the Z-DNA binding proteins in E. coli were performed in the recA protein free strain [7]. This result suggested that there is another type of Z-DNA binding protein beside recA protein. However, we found Z-DNA binding domain only in recA protein in E. coli, so this point is not clear.

Ideally, taxonomic classification should reflect the evolutionary history of the organism for the presence/absence of Z-DNA binding domain. If organisms A and B are phylogenetically close enough, it is expected that both organisms A and B have Z-DNA binding domain or not. This expectation varied among organisms as follows. There were 71 organisms in the section of betaproteobacteria and 24 organisms belong to Bundrkholderia species. Only Burkholderia xenovorans indicated the presence of Z-DNA binding 
domain, and other organisms indicated the absence of this domain. There were 49 vertebrates in the section of eumetazoa in eukaryotes. 43 vertebrates showed the presence of Z-DNA binding domain and 6 vertebrates including chicken showed the absence of this domain. It is reported that chicken has Z-DNA binding protein [9], but our results indicated the absence of this domain in chicken. This point is not clear. In eukaryotes, only vertebrates had the Z-DNA binding domain. The acquisition of this domain in vertebrates would be caused by horizontal gene transfer (HGT) [34-36]. Isolated occurrence of Z-DNA binding domain in ADAR from human in distantly related species of archaea and bacteria suggested that the gene of this domain might have arrived via an HGT event.

It is considered that if the function of a protein is essential, the protein would be conserved. The Z-DNA binding domain in recA protein from $E$. coli was conserved in all the organisms. This result indicated that the function of this domain is essential. Another type of the Z-DNA binding domain in ADAR from human was observed in some organisms in archaea, bacteria and eukaryotes. This result suggested that the function of this domain is non-essential, even though the biological function of this domain is not clearly understood.

Unfortunately, GTOP database has not been updated since 2010 October 6. However, GTOP offers valuable information on Z-DNA binding domains. As far as we examined, there was no database like GTOP with useful keyword search. There are two types of Z-DNA binding domains and some organisms have both domains. However, it seems that most researchers do not distinguish $E$. coli type or human type Z-DNA binding domain they are analyzing. To study the function of this domain, it is necessary to discern which type of this domain they are studying.

\section{CONFLICTS OF INTEREST}

The author declares no conflicts of interest regarding the publication of this paper.

\section{REFERENCES}

1. Rich, A., Nordheim, A. and Wang, A.H.-J. (1984) The Chemistry and Biology of Left-Handed Z-DNA. Annual Review of Biochemistry, 53, 791-846. https://doi.org/10.1146/annurev.bi.53.070184.004043

2. Nordheim, A., Tesser, P., Azorin, F., Kwon, Y.H., Möller A. and Rich, A. (1982) Isolation of Drosophila proteins That Bind Selectively to Left-Handed Z-DNA. Proceedings of the National Academy of Sciences of the United States of America, 79, 7729-7733. https://doi.org/10.1073/pnas.79.24.7729

3. Kuenzle, C.C., Heizmann, C.W., Hübscher, U., Hobi, R., Winkler, G.C. Jaeger, A.W. and Morgenegg, G. (1983) Chromatin Changes Accompanying Neuronal Differentiation. Cold Spring Harbor Symposia on Quantitative Biology, 48, 493-499. https://doi.org/10.1101/SQB.1983.048.01.054

4. Lafer, E.M., Sousa, R., Rosen, B., Hsu, A. and Rich, A. (1985) Isolation and Characterization of Z-DNA Binding Proteins from Wheat Germ. Biochemistry, 24, 5070-5076. https://doi.org/10.1021/bi00340a017

5. Gut, S.H., Bischoff, M., Hobi, R. and Kuenzle, C.C. (1987) Z-DNA-Binding Proteins from Bull Testis. Nucleic Acids Research, 15, 9691-9705. https://doi.org/10.1093/nar/15.23.9691

6. Blaho, J.A. and Wells, R.D. (1987) Left-Handed Z-DNA Binding by the recA Protein of Escherichia coli. The Journal of Biological Chemistry, 262, 6082-6088.

7. Jaworski, A., Hsieh, W.-T., Blaho, J.A., Larson, J.E. and Wells, R.D. (1987) Left-Handed DNA in Vivo. Science, 238, 773-777. https://doi.org/10.1126/science.3313728

8. Kitayama, S., Matsumura, O. and Masuda, S. (1988) Isolation of a DNA-Binding Protein from Deinococcus radiodurans Having an Affinity for a Z-Form Polynucleotide. The Journal of Biochemistry, 104, 127-130. https://doi.org/10.1093/oxfordjournals.jbchem.a122407

9. Herbert, A.G., Spitzner, J.R., Lowenhaupt, K. and Rich, A (1993) Z-DNA Binding Protein from Chicken Blood Nuclei. Proceedings of the National Academy of Sciences of the United States of America, 90, 3339-3342. 
https://doi.org/10.1073/pnas.90.8.3339

10. Herbert, A., Alfken, J., Kim, Y.-G., Mian, I.S., Nishikura, K. and Rich, A (1997) A Z-DNA Binding Domain Present in the Human Editing Enzyme, Double-Stranded RNA Adenosine Deaminase. Proceedings of the National Academy of Sciences of the United States of America, 94, 8421-8426. https://doi.org/10.1073/pnas.94.16.8421

11. Schwartz, T., Rould, M.A., Lowenhaupt, K., Herbert, A. and Rich, A. (1999) Crystal Structure of the Z $\beta$ Domain of the Human Editing Enzyme ADAR1 Bound to Left-Handed Z-DNA. Science, 284, 1841-1845. https://doi.org/10.1126/science.284.5421.1841

12. Schade, M., Turner, C.J., Kühne, R., Schmieder, P., Lowenhaupt, K., Herbert, A., Rich, A. and Oschkinat, H. (1999) The Solution Structure of the Z $\beta$ Domain of the Human RNA Editing Enzyme ADAR1 Reveals a Prepositioned Binding Surface for Z-DNA. Proceedings of the National Academy of Sciences of the United States of America, 96, 12465-12470. https://doi.org/10.1073/pnas.96.22.12465

13. Kim, H.-E, Ahn, H.-C., Lee, Y.-M., Lee, E.-H., Seo, Y.-J., Kim, Y.-G., Kim, K.K., Choi, B.-S. and Lee, J.-H. (2011) The Z $\beta$ Domain of Human DAI Binds to Z-DNA via a Novel B-Z Transition Pathway. FEBS Letters, 585, 772-778. https://doi.org/10.1016/j.febslet.2011.01.043

14. Kim, K., Khayrutdinov, B.I., Lee, C.-K., Cheong, H.-K., Kang, S.W., Park, H., Lee, S., Kim, Y.-G., Jee, J., Rich, A., Kim, K.K. and Jeon, Y.H. (2011) Solution Structure of the Z $\beta$ Domain of Human DNA-Dependent Activator of IFN-Regulatory Factors and Its Binding Modes to B- and Z-DNAs. Proceedings of the National Academy of Sciences of the United States of America, 108, 6921-6926. https://doi.org/10.1073/pnas.1014898107

15. Story, R.M., Weber, I.T. and Steitz, T.A. (1992) The Structure of the E. coli recA Protein Monomer and Polymer. Nature, 355, 318-325. https://doi.org/10.1038/355318a0

16. Oh, D.-B., Kim, Y.-G. and Rich, A. (2002) Z-DNA-Binding Proteins Can Act as Potent Effectors of Gene Expression in Vivo. Proceedings of the National Academy of Sciences of the United States of America, 99, 16666-16671. https://doi.org/10.1073/pnas.262672699

17. Kawabata, T., Fukuchi, S., Homma, K., Ota, M., Araki, J., Ito, T., Ichiyoshi, N. and Nishikawa, K. (2002) GTOP: A Database of Protein Structures Predicted from Genome Sequences. Nucleic Acids Research, 30, 294-298. https://doi.org/10.1093/nar/30.1.294

18. Fukuchi, S., Homma, K., Sakamoto, S., Sugawara, H., Tateno, Y., Gojobori, T. and Nishikawa, K. (2009) The GTOP Database in 2009: Updated Content and Novel Features to Expand and Deepen Insights into Protein Structures and Functions. Nucleic Acids Research, 37, D333-D337. https://doi.org/10.1093/nar/gkn855

19. Berman, H.M., Westbrook, J., Feng, Z., Gilliland, G., Bhat, T.N., Weissig, H., Shindyalov, I.N. and Bourne, P.E. (2000) The Protein Data Bank. Nucleic Acids Research, 28, 235-242. https://doi.org/10.1093/nar/28.1.235

20. Westbrook, J., Feng, Z., Jain, S., Bhat, T.N., Thanki, N., Ravichandran, V., Gilliland, G.L., Bluhm, W.F., Weissig, H., Greer, D.S., Bourne, P.E. and Berman, H.M. (2002) The Protein Data Bank: Unifying the Archive. Nucleic Acids Research, 30, 245-248. https://doi.org/10.1093/nar/30.1.245

21. Murzin, A.G., Brenner, S.E., Hubbard, T. and Chothia, C. (1995) SCOP: A Structural Classification of Proteins Database for the Investigation of Sequences and Structures. Journal of Molecular Biology, 247, 536-540. https://doi.org/10.1016/S0022-2836(05)80134-2

22. Bairoch, A. and Apweiler, R. (2000) The SWISS-PROT Protein Sequence Database and Its Supplement TrEMBL in 2000. Nucleic Acids Research, 28, 45-48. https://doi.org/10.1093/nar/28.1.45

23. Woese, C.R. and Fox, G.E. (1977) Phylogenetic Structure of the Prokaryotic Domain: The Primary Kingdoms. Proceedings of the National Academy of Sciences of the United States of America, 74, 5088-5090. https://doi.org/10.1073/pnas.74.11.5088 
24. Muller, F., Brissac, T., Le Bris, N., Felbeck, H. and Gros, O. (2010) First Description of Giant Archaea (Thaumarchaeota) Associated with Putative Bacterial Ectosymbionts in a Sulfidic Marine Habitat. Environmental Microbiology, 12, 2371-2383. https://doi.org/10.1111/j.1462-2920.2010.02309.x

25. Gupta, R.S. (1998) Protein Phylogenies and Signature Sequences: A Reappraisal of Evolutionary Relationship among Archaebacteria, Eubacteria, and Eukaryotes. Microbiology and Molecular Biology Reviews, 62, 1435-1491.

26. Nishikura K. (2010) Functions and Regulations of RNA Editing by ADAR Deaminases. Annual Review of Biochemistry, 79, 321-349. https://doi.org/10.1146/annurev-biochem-060208-105251

27. Samuel, C.E. (2011) Adenosine Deaminases Acting on RNA (ADARs) Are Both Antiviral and Proviral Dependent upon the Virus. Virology, 411, 180-193. https://doi.org/10.1016/j.virol.2010.12.004

28. Tonkin, L.A., Saccomanno, L., Morse, D.P., Brodigan, T., Krause, M. and Bass, B.L. (2002) RNA Editing by ADARs Is Important for Normal Behavior in Caenorhabditis elegans. The EMBO Journal, 21, 6025-6035. https://doi.org/10.1093/emboj/cdf607

29. Palladino, M.J., Keegan, L.P., O’Connell, M.A. and Reenan, R.A. (2000) dADAR, a Drosophila Double-Stranded RNA-Specific Adenosine Deaminase Is Highly Developmentally Regulated and Is Itself a Target for RNA Editing. $R N A, 6$, 1004-1018. https://doi.org/10.1017/S1355838200000248

30. Palavicini, J.P., O’Connell, M.A. and Rosenthal, J.J.C. (2009) An Extra Double-Stranded RNA Binding Domain Confers High Activity to a Squid RNA Editing Enzyme. RNA, 15, 1208-1218. https://doi.org/10.1261/rna.1471209

31. Savva, Y.A., Rieder, L.E. and Reenan, R.A. (2012) The ADAR Protein Family. Genome Biology, 13, 252. https://doi.org/10.1186/gb-2012-13-12-252

32. Köhler, M., Burnashev, N., Sakmann, B. and Seeburg, P.H. (1993) Determinants of Ca ${ }^{2+}$ Permeability in Both TM1 and TM2 of High Affinity Kainite Receptor Channels: Diversity by RNA Editing. Neuron, 10, 491-500. https://doi.org/10.1016/0896-6273(93)90336-P

33. Burns, C.M., Chu, H., Rueter, S.M., Hutchinson, L.K., Canton, H., Sanders-Bush, E. and Emeson, R.B. (1997) Regulation of Seletonin-2C Receptor G-Protein Coupling by RNA Editing. Nature, 387, 303-308. https://doi.org/10.1038/387303a0

34. Ochman, H., Lawrence, J.G. and Groisman, E.A. (2000) Lateral Gene Transfer and the Nature of Bacterial Innovation. Nature, 405, 299-304. https://doi.org/10.1038/35012500

35. Ochman, H., Lerat, E. and Daubin, V. (2005) Examining Bacterial Species under the Specter of Gene Transfer and Exchange. Proceedings of the National Academy of Sciences of the United States of America, 102 , 6595-6599. https://doi.org/10.1073/pnas.0502035102

36. Ravenhall, M., Skunca, N., Lassalle, F. and Dessimoz, C. (2015) Inferring Horizontal Gene Transfer. PLoS Computational Biology, 11, e1004095. https://doi.org/10.1371/journal.pcbi.1004095 